\section{Entre fenomenologia e hermenêutica: a condição responsiva da subjetividade}

\author{
Marcelo Fabri ${ }^{1}$ \\ Professor do Departamento de \\ Filosofia da UFSM - \\ Santa Maria - RS
}

\author{
Between phenomenology and \\ hermeneutics: \\ subjectivity's responsive \\ condition
}

Resumo: $\mathrm{O}$ artigo explora a relação entre fenomenologia e hermenêutica a partir da estrutura responsiva da subjetividade humana. Mesmo em sua proposta de um "retorno" ao mundo da vida, Husserl não abre mão de um eu constituinte que, ao realizar a redução, parece suspender $\mathrm{O}$ movimento real da vida e da linguagem. Como pode o mundo como solo fundador ser algo constituído pelo ego? Eis o paradoxo: para se recuperar o solo fundador de toda ciência é fundamental reconhecer a pureza transcendental do ego constituinte. A pergunta que colocamos, no entanto, é esta: a referida "pureza" transcendental significa um empecilho à abertura dialógica proposta pela hermenêutica filosófica? Cumpre mostrar que não, pois, pensadas a partir da unicidade respondente (subjetividade humana), fenomenologia transcendental e atitude dialógica (hermenêutica) tornam-se modelos teóricos que, mesmo muito diferentes um do outro, fecundam-se ou se enriquecem mutuamente.

Palavras-chave: fenomenologia, hermenêutica, transcendental, responsividade, diálogo
Abstract: This paper aims to explore the relation between phenomenology and hermeneutics according to the responsive structure of the human subjectivity. Although Husserl proposes a "comeback" to the world of life, he does not give up of a constitutional Ego which, at the moment it makes the reduction, seems to suspend the real movement of life and of language. How could the world as a foundational ground to be something constituted by the ego? Here lies the paradox: to recover the foundational ground of all science is fundamental to recognize the transcendental purity of the constitutional Ego. However the question we highlight is the following: does this called transcendental "purity" mean an obstacle to the dialogical proposed by the philosophical hermeneutics? We shall demonstrate that no, because if we think them based on the respondent singularity (human subjectivity), transcendental phenomenology and dialogical attitude (hermeneutics) become theoretical models that enrich themselves mutually, even if very different from each other.

Keywords: phenomenology, hermeneutics, transcendental, responsivity, dialogue

\footnotetext{
1 e-mail: fabri.ufsm@gmail.com.
} 
A fenomenologia e a hermenêutica são recursos metodológicos de extrema atualidade para se pensar a condição responsiva e dialógica da realidade humana. São, no entanto, propostas muito diferentes. A fenomenologia (pelo menos a de Husserl) se prende a um conceito de transcendental que jamais prescinde da referência a um ego constituinte, livre para realizar a redução [epoché]. A hermenêutica, por sua vez, não abre mão da situação de linguagem, questionando enfaticamente a primazia do sujeito transcendental, entendido como constituinte absoluto do mundo, em sua significação objetiva e intersubjetiva. Para Gadamer, a ênfase sobre o eu transcendental, mantida por Husserl até mesmo em sua obra de maturidade, em que o mundo da vida vem exaustivamente nomeado e pensado, não diminui a dificuldade de se considerar o "tu" e o "nós" a partir do conceito de constituição, no qual o ego é a figura eminente (GADAMER, 2012: 178). A referência ao mundo da vida, solo fundador de todo conhecimento elaborado pelas ciências, não abandona o recurso à atitude metódica que "põe fora de jogo" o mundo pré-dado, que faz deste solo um fenômeno para a consciência, elevando o eu acima do mundo (HUSSERL, 2012, S 41: 124). Husserl objetaria: é esta elevação que nos faz reencontrar (recordar) aquilo que está mais próximo de nós, que compreendemos previamente, solo fundador de toda teoria, mundo da vida que foi transformado pela civilização tecnológica. Pode-se perguntar se não é a motivação autêntica de Husserl que a hermenêutica filosófica pretende explorar (GADAMER, 2012: 230). Tudo se passa como se a hermenêutica lançasse luz sobre um mundo que Husserl "tirou do esquecimento", mas do qual sempre se distanciou, tendo em vista sua obsessão pela constituição transcendental do próprio mundo. Por outro lado, a fenomenologia parece "tirar do esquecimento" algo que a hermenêutica, por princípio, deixa de lado: a necessidade de um "espaço transcendental" mínimo, a língua universal capaz de realizar a mediação das diferentes línguas. Mas, eis a nossa tese, somente a fenomenologia da subjetividade respondente poderia pensar a articulação dessas propostas tão diferentes e contrastantes.

\section{Reminiscência}

Husserl concebeu a filosofia como autorrealização da humanidade. Entrar no domínio da razão filosófica implica engajar-se pela ideia de verdade numa tarefa que jamais encontra termo. Mas, para que tal entrada se consolide num trabalho coerente e eficaz, é preciso vencer os prejuízos da atitude natural realizando a epoché. Só assim se poderia chegar a uma ciência inteiramente nova, que não é outra senão a ciência subjetiva voltada para o próprio eu transcendental. A filosofia se compreende como luta incessante da razão, um movimento sempre renovado de aclaramento, pelo qual o ideal mais caro à Filosofia do Ocidente (o ideal de saber rigoroso) é assumido por uma vida pessoal comprometida com a verdade e a liberdade. No intuito de evitar o domínio

Revista de Filosofia Moderna e Contemporânea

Brasília, vol 3, no 2, 2015. 
técnico sobre o pensamento e a vida, é necessário "recordar" o fundamento humano da ciência. O que se busca, em última instância, é um sentido de racionalidade marginalizado e esquecido pelas ciências.

O que se encontra esquecido? Aquilo que é mais próximo de nós. Aquilo que é primordial: a intuição, sempre relativa a subjetividades concretas, num mundo précientífico. Este mundo relativo, isto é, que sempre pressupõe nossas percepções, avaliações, recordações etc., é esquecido pelos homens de ciência, mas tal esquecimento não pode contornar o fato de que "as ciências estão construídas sobre a obviedade do mundo da vida" (HUSSERL, 2012, \34: 102). Certo, aquilo que é apenas "relativamente ao sujeito" deve ser ultrapassado pelo olhar objetivo da ciência, mas o domínio das evidências originárias é o pressuposto "subjetivo" e concreto desse olhar. Nem mesmo as idealidades da lógica pura, que são "verdades em si", poderiam dispensar a fundação de todo o saber objetivo no assim chamado mundo da vida. Pois as idealidades não alteram o fato de que "as teorias são configurações humanas, essencialmente referentes a atualidades e potencialidades humanas" (HUSSERL, 2012, \34: 106).

Temos, então, o problema: como "fazer justiça" a este mundo pré-dado, entendido como solo fundador de toda teoria, de tudo o que é verdadeiro do ponto de vista científico? Como devemos compreendê-lo ou, pelo menos, valorizá-lo devidamente? Mais ainda: como encontrar uma cientificidade adequada a ele? Nas palavras de Husserl: "A paradoxal referência mútua entre o 'mundo objetivamente verdadeiro' e o 'mundo da vida' torna enigmático o modo de ser de ambos" (HUSSERL, 2012, ] 34.: 107). Ora, o que entender por mundo verdadeiro? Mundo científico e mundo da vida não possuem o seu próprio modo de ser, a sua especificidade? Pois bem, na medida em que se realiza a epoché em relação ao mundo das ciências, o ego volta seus olhos para as relatividades do mundo em que já sempre vivemos. Descobre-se, assim, que não há um mundo da vida, único para todos, mas mundos, outras referências valorativas, outros universos culturais. Por outro lado, é preciso considerar o seguinte. $\mathrm{O}$ esforço de reminiscência implica não só a lembrança do mundo em que vivemos, ou das diferenças infindáveis das várias formas culturais de vida, mas também a "recordação" do caminho da própria ciência, do olhar objetivo para o mundo. Como assim?

É que, para além das verdades cientificas, supostamente objetivas, isto é, das verdades de ninguém em particular, há verdades concernentes ao próprio mundo das relatividades, àquilo que é comum a todos os povos e culturas. Não aquilo que sintetiza as diferenças numa universalidade que superou toda particularidade, mas as "verdades" referentes às particularidades. $\mathrm{O}$ pensamento de Husserl chega, aqui, a um limite intransponível. Só se pode trazer à tona o que foi esquecido pelo olhar objetivo da ciência se houver uma analogia entre o olhar objetivo, proposto pelas ciências, e a generalidade, passível de explicitação, do próprio mundo da vida. Pois, para Husserl, também o mundo da vida possui a sua estrutura geral, aquilo que é comum aos vários mundos, supostamente tão diferentes. Todos esses mundos possuem objetos tais como "figura espacial", movimento, qualidades sensíveis

Revista de Filosofia Moderna e Contemporânea

Brasília, vol 3, no 2, 2015. 
etc.. Eis o que abre caminho para a ciência objetiva. Todo ser relativo está vinculado a uma estrutura geral oferecida pelo próprio mundo da vida. As estruturas a priori necessárias às verdades em si da ciência têm seu correspondente na estrutura geral do mundo da vida. Nas palavras de Husserl:

\section{Aquilo que a configuração de sentido e a validade de ser de nivel superior do a priori matemático e de todo o a priori objetivo produzem é uma certa operação idealizadora, com base no a priori do mundo da vida (HUSSERL, 2012, I 36:114).}

O que se traz à memória, portanto, não é a vida em seu movimento, a linguagem em sua peculiaridade, as obras humanas com sua beleza e variedade, mas um novo a priori, uma nova estrutura geral, base fundadora de todos os outros a priori, de que se beneficiam a lógica, as matemáticas e as ciências. O mundo é o "solo" de tudo o que fazemos, conhecemos e vivemos. Nós já sempre estamos na certeza do mundo. Vivemos nesta certeza e a partir dela. Todos os objetos nos são "dados" a partir desse horizonte do mundo. Mas o mundo não é um objeto. Ele é o horizonte a partir do qual algo nos pode afetar, mas também pelo qual podemos agir. Como podemos fazer deste mundo um tema, ou ainda: como podemos observá-lo? Saindo dele. Mas de que modo, se é dele que tudo depende, provém ou tem início para nós? A resposta de Husserl, a esse respeito, resume seu pensamento: "A vida que realiza a validade do mundo, validade própria da vida natural do mundo, não se deixa estudar na atitude desta vida natural do mundo" (HUSSERL, 2012, \39: 121).
O sujeito que vive no mundo está sempre direcionado a algo, está ativamente presente em seus atos, numa palavra, está sempre ocupado com alguma coisa, envolvido por aquilo que o circunda, imerso numa comunidade etc. É aí neste mundo que tomamos posição sobre isto ou aquilo, ou seja, que estamos imersos num processo sempre renovado de validações teóricas ou práticas. Ao suspendermos metodicamente esta vida naturalmente imersa no mundo, o olhar filosófico se torna livre de seu vínculo mais forte, mais fundamental, mais universal. Descobre-se como subjetividade transcendental, realizadora da própria validade do mundo (HUSSERL, 2012, \ 41: 123).

Todos os assim chamados interesses naturais foram suspensos, postos fora de jogo. Mas o mundo não desapareceu. Ele apenas se tornou um "correlato da subjetividade para ele doadora de sentido de ser, subjetividade por cuja validade ele em geral 'é' “(HUSSERL, 2012, \41: 124). $O$ sujeito se encontra, assim, acima do mundo, ou seja, o mundo se tornou para ele simples fenômeno.

Mas este "estar acima do mundo" não significa ter abandonado o mundo faticamente, empiricamente, realmente. Ao contrário: é a condição para que o sujeito se descubra como sendo sempre e inevitavelmente "um ponto de vista sobre o mundo", um modo de perceber o que o envolve, bem como o âmbito no qual vive. Numa palavra, tornar o mundo relativamente ao sujeito, pela redução, é apontar para as várias maneiras subjetivas de doação, de modos de aparecer. Seja real ou não, um ente tem sempre as suas formas próprias de doação e de aparição. A intencionalidade é a chave para toda explicação genuína, ou

Revista de Filosofia Moderna e Contemporânea

Brasília, vol 3, no 2, 2015. 
ainda: é o conceito com o qual se torna possível qualquer compreensibilidade. Se permanecermos na atitude natural, ou seja, se não realizamos a epoché, caímos numa espécie de desconhecimento sistemático de nós mesmos e do próprio mundo em que vivemos. Desconhecemos, igualmente, o fato de que a subjetividade na qual tudo termina se centrando, só é o que é graças à intersubjetividade. Eis por que é preciso buscar não somente a simultaneidade dos vários sujeitos, mas também e, sobretudo, a sociabilidade universal, ou seja, o "espaço" de todos os sujeitos pensados do ponto de vista do polo eu (HUSSERL, 2012 \50: 141).

\section{Responsividade}

Ora, o método redutivo, que suspende as crenças voltadas ao mundo da vida, termina isolando, artificialmente ou abstratamente, o ego na assim chamada esfera própria. Enquanto se observa a si mesmo em suas operações intencionais direcionadas a seus correlatos, o ego se descobre numa espécie de solidão monádica, isto é, compreende que a redução o põe em contato exclusivo com aquilo que lhe pertence, não o autorizando a experimentar nada que tenha o sentido de não-propriedade [Nichteigene] ou de exterioridade. Tudo o que seja predicado do mundo objetivo e das pessoas que nele se encontram deve, pois, ser colocado entre parênteses, ou fora do jogo, pela redução transcendental. $O$ sentido "objetivo" desaparece, e com ele tudo o que se relaciona à esfera de intersubjetividade, sem a qual este "objetivo" não poderia ser constituído (HUSSERL, \44, 2013: 134).

Paradoxalmente, em vez de um sujeito distanciado do mundo ou desencarnado, a fenomenologia procura recuperar a experiência corporal vivida, aquela que manifesta uma relação sensível com tudo o que nos cerca, manifestação de mobilidade e, consequentemente, de liberdade. Ponho e disponho de meu corpo. Ele é o órgão do querer, ele me ensina sobre minhas próprias possibilidades perceptivas e cognitivas, numa palavra, o corpo próprio [Leib] é sinônimo de "eu posso". Meu corpo se encontra, portanto, reduzido à minha esfera de propriedade e, por causa disto, o mundo enquanto um "nós", enquanto mundo comum a vários indivíduos de que eu mesmo faço parte como ser social e cultural, também foi posto fora de jogo. Por isso, os outros com quem partilho as experiências no interior do mundo foram também separados de mim, graças a uma espécie de abstração (HUSSERL, \44, 2013: 136). Surge, assim, a questão: como é que tal "separação" abstrata poderia reconbecer algo de "outro" em relação a ela? Qual seria a primeira experiência de "alteridade"?

Tudo o que foi reduzido ou separado metodicamente estará vinculado a uma experiência transcendental, apropriada pelo próprio eu. Tudo o que é exterior é, em certo sentido, correlacionado à esfera de propriedade. Tudo, em certo sentido, me pertence. $\mathrm{O}$ que resistiria a esta vinculação, a esta apropriação egológica? $O$ que poderia fornecer a mim, ego que realiza a meditação, um sentido de "exterioridade", de "mundo objetivo", um "fora" de meu mundo próprio? A resposta é óbvia: uma esfera que não fosse redutível às minhas vivências, à minha imanência. $\mathrm{O}$ corpo do outro aparece em minha esfera de propriedade, mas o outro eu possui, ele também, a sua esfera de propriedade. $\mathrm{O}$ conceito de esfera própria pressupõe o

Revista de Filosofia Moderna e Contemporânea

Brasília, vol 3, no 2, 2015. 
conceito de estrangeiro, de alteridade, de algo inacessível para mim.

O que Husserl descobre, portanto, é que a relação intersubjetiva, que faz do mundo algo comum e objetivado, não é uma atividade sintética da consciência, não é uma unificação de diferenças realizada por um sujeito histórico, porta-voz da razão universal, e sim associação, possibilidade de formação de pluralidade. O mundo objetivo (de todos) é sempre e necessariamente mundo de vários "eu" em relação e interação. $\mathrm{O}$ mundo objetivo é o correlato de uma experiência intersubjetiva, idealmente concordante. Não fosse a percepção do "outro" como estrangeiro, ou não-próprio, a formação de uma comunidade estaria comprometida. Ora, o mundo objetivo já me foi dado antes mesmo que eu refletisse sobre ele. Mas a redução, que me separa desse mundo apenas artificialmente, faz ver que o ponto de partida para se compreender o social e o coletivo não é algo "comum", e sim a experiência do "estrangeiro" como tal. Explica Waldenfels:

$\mathrm{Na}$ sua análise da experiência fenomenológica, Husserl não parte da experiência comum, nem mesmo da experiência daquilo que é comum, mas sim da experiência do estrangeiro enquanto estrangeiro. O que se encontra no início não é a bumanidade em cada pessoa, nem mesmo a estraneidade na minha pessoa, mas sim a humanidade no "outro": "O primeiro homem é o outro, e não $\mathrm{eu}^{2}$ " WALDENFELS, 2002: 112. grifos do autor).
$\mathrm{Na}$ perspectiva de Waldenfels, a alteridade do outro se anuncia sob a forma de um pathos. Do ponto de vista do corpo [Leib], o outro existe em mim e me precede. Por isso, nós nos sentimos tocados pelos outros antes mesmo de perguntar o que as suas expressões são e significam. A estraneidade do outro nos surpreende, nos desestabiliza. O outro existe co-originariamente a mim. A estraneidade do outro embaraça nossa intencionalidade primeira. Mesmo sendo meu semelhante, o estrangeiro é fora de série, é incomparável. A razão, em sua busca de compreensão e intelecção, seria insuficiente para se proteger deste abalo, para dominá-lo. O ser corpóreo faz que o semelhante seja outro, seja único. No outro e através do outro, eu me reduplico. A estraneidade estática de mim mesmo pode dar-se através da estraneidade duplicativa do outro. O olhar estranho a que estou exposto concorre para que eu me sinta visto antes de notar que ele vê coisas e me vê. Esta condição põe em questão toda pretensão de uma filosofia transcendental. Não se pode fazer a experiência do estrangeiro, nem por mim mesmo nem pelas regras universais ou gerais. Trata-se de uma "experiência" não pensável previamente.

Não há indivíduos prontos e constituídos. "Aquilo que sentimos, percebemos, fazemos ou dizemos é - como em um tapete tibetano - imbricado com aquilo que os outros sentem, percebem, fazem ou dizem" (WALDENFELS, 2008: 102). Recebemos o próprio nome de outros. Há um inominado em nós. O corpo é lugar de transição: natureza e cultura, ação e paixão,

2 A última frase é do próprio Husserl, em Zur Phänomenologie der Intersubjektivität. Texte aus dem Nachlass II: 1921-1926 (Husserliana XIV), Den Haag: Nijhoff, 1973, p. 418. (Apud WALDENFELS, 2002: 112).

Revista de Filosofia Moderna e Contemporânea

Brasília, vol 3, no 2, 2015. 
o próprio se muda em estranho e viceversa. Eis por que o discurso sobre o corpo próprio contém apenas meia verdade. $O$ corpo próprio pode ser designado como semi-estranho, uma vez que é atravessado por intenções estrangeiras, além de projetos, hábitos, afecções e lesões que provêm de outros. O outro e os outros estão em mim. Eu me encontro neles. E isso não é uma situação de diálogo. Por conseguinte, encontrar o outro frontalmente é não-estar-no-mesmo-plano. Como responder ao apelo que vem do não-próprio? Eis a dificuldade ética de uma fenomenologia responsiva.

Para haver diálogo, em sentido clássico, uma assimetria já deve ter ocorrido. Assimetria de pergunta e resposta. O diálogo que nós sempre somos provém de uma distância, de um estranhamento, de uma demanda que precede uma relação em que os interlocutores se encontram no mesmo plano. A demanda que vem do estrangeiro implica um destinatário, uma ipseidade respondente, um sujeito que se descobre no acusativo. $O$ responder não começa com o falar sobre alguma coisa. Nem mesmo o falar em geral o explica. Por quê? Porque responder tem início com o "voltar o olhar e prestar ouvidos, os quais possuem uma forma própria de inevitabilidade" (WALDENFELS, 2008: 70). Obedecer ao imperativo da resposta implica, paradoxalmente, já tê-lo obedecido. A resposta pode ser automática, um gesto mecânico de pura prevenção, de pura defesa. Mas, enquanto tal, o responder não é orientado previamente, não recai sob o domínio de regras. Por isso, o ser humano não é apenas como tradicionalmente se diz um animal dotado de logos, mas também e, fundamentalmente, um animal que dá respostas (WALDENFELS, 2008: 72).

\section{Diálogo}

Husserl parece não abrir mão jamais de uma segurança transcendental. A fenomenologia responsiva, por sua vez, descreve, graças ao método inaugurado por Husserl, o abalo desta segurança. E a hermenêutica? Ela aponta para uma exigência não menos arriscada e difícil. Trata-se de se reconhecer que não há horizonte fixo, que, na abertura dialógica, nós nos colocamos à prova, e isto vale para nossos conceitos e tudo aquilo que supostamente compreendemos. Sem este "desprendimento", os horizontes jamais poderiam se "fundir", se alargar a partir do encontro. A finitude é, então, o limite. Todo o projeto visando compreensão mútua está marcado, desde o início, pela insegurança, pela incerteza.

Em meio à fragilidade e à vulnerabilidade que constituem a condição humana, a hermenêutica aposta numa crença fundamental. $O$ verdadeiro valor, afirma Gadamer, é o próprio diálogo. Ou seja, não se trata de valorizar a particularidade dos interlocutores, mas a capacidade de seguir o diálogo (GADAMER, 2000: 757). A verdade supõe o logos, que não é de nenhum interlocutor em particular, mas algo que os envolve, que os transforma e, sobretudo, que os guia. Ao final das contas, o verdadeiro meio para a compreensão mútua é a linguagem. Ora, não é justamente esta aufhebung que vem posta em causa pela fenomenologia transcendental e, mais duramente, pela fenomenologia responsiva? Eis o ponto. Na perspectiva hermenêutica, trata-se também de escapar à prisão na linguagem, mas para tanto é preciso realizar a própria experiência hermenêutica (GADAMER, 2000: 821).

Revista de Filosofia Moderna e Contemporânea

Brasília, vol 3, no 2, 2015. 
Como, então, reconhecer minha responsabilidade nesta experiência? Posso me reconhecer a mim mesmo naquilo que testemunho ou prometo, naquilo que digo ou realizo, etc. Posso dizer e responder sobre o que digo. Reconheço-me em minhas próprias possibilidades (RICOEUR, 2006: 109). Quando fazemos isto, não somos mais um termo lexical no sistema da língua, pois sabemos que, ao usar o pronome pessoal "eu" quando falamos, já está em questão um "insubstituível" (RICOEUR, 2006: 109) É deste modo que "a estrutura pergunta-resposta constitui a estrutura básica do discurso enquanto implicando locutor e interlocutor" (RICOEUR, 2006: 111). Mas se uma ipseidade respondente é imprescindível, a filosofia do diálogo não abre mão da busca de uma morada comum, com a qual se tem familiaridade e na qual é possível mover-se juntos (GADAMER, 2005: 110).

A busca da morada comum não anula a assimetria entre o um e o outro? Entremos no argumento de Gadamer. Falar supõe o encontro com uma alteridade, o "estar diante do outro". Mas a linguagem enquanto práxis é um "comércio" que aspira à compreensão, à saída de uma limitação. É nesse sentido que a linguagem deixa de ser apenas proposição e juízo, uma vez que é, principalmente, resposta e pergunta. Mais do que saber, está em jogo o compreender. $\mathrm{Na}$ perspectiva hermenêutica, a linguagem não é simples comunicação de mensagens, troca de signos. Ela é um "estar a caminho". Em direção a quê? $\mathrm{Na}$ direção do outro [Miteinander] e no intuito de nos compreendermos a nós mesmos no mundo. Compreender-se no mundo quer dizer não só compreender-se com o outro, mas compreender o outro.
Trata-se da mais árdua tarefa humana, tanto mais para nós que vivemos num mundo marcado por ciências monológicas. As ciências são um único e grande monólogo e são orgulhosas disso (GADAMER, 2005: 81).

Orgulhosas porquanto capazes de oferecer segurança e controle, sobretudo no que diz respeito às surpresas do outro. $\mathrm{E}$, no entanto, é este outro imprevisível que nos traz a possibilidade de questionar nosso amor-próprio e nosso egocentrismo. $\mathrm{O}$ problema é ético-político, diz respeito a algo que vai além de qualquer particularidade, numa palavra, possui um alcance universal. Por quê? Porque se trata do desejo que possuímos de nos compreender mutuamente, de nos fazer entender, de compreendermos a nós mesmos e aos outros. O outro é aquele que pode nos responder, nos confirmar, nos corrigir.

\section{Quem escuta o outro escuta sempre alguém que possui o próprio horizonte. Entre en e tu acontece a mesma coisa que entre povos ou entre esferas culturais $e$ as tradiçoes religiosas. Encontramo-nos onde estivermos diante do mesmo problema: devemos aprender que na escuta do outro se abre o verdadeiro caminho sobre o qual a solidariedade se edifica (GADAMER, 2005: 81).}

Em vez de racionalização e burocratização, o que se dá é um movimento de escuta, de respeito, de cuidado em relação ao outro. Trata-se de um movimento de escuta recíproca, que, evidentemente, contrasta com um mundo de especialistas. Para Gadamer, é certo que existem especialistas que sabem escutar as necessidades da sociedade e da humanidade, mas isto já faz

Revista de Filosofia Moderna e Contemporânea

Brasília, vol 3, no 2, 2015. 
deles algo diferente de indivíduos voltados para uma especialidade. Eles fazem isso enquanto motivados por uma espécie de sentimento de responsabilidade pela humanidade ( $c$. GADAMER, 2005: 82), pelos seus destinos, pela diversidade dos horizontes. Eis por que é preciso realizar mediação, tradução, interpretação. Tudo depende do tradutor, daquele que realiza a mediação entre dois mundos diferentes, ou do trabalho de audição de mundos diferentes um para o outro, no desejo de compreender-se mutuamente. Buscar um terreno, comum, afirma Gadamer (GADAMER, 2005: 83).

Para o filósofo do diálogo, a tarefa da filosofia nos dias de hoje é enfrentar o desafio da pluralidade das línguas, é buscar o papel do tradutor, em vez da planificação e da programação racionalizante que parece imperar. É compreender o espaço do "estrangeiro" [Fremd] por referência ao movimento do diálogo, ao in Gespräch sein. Mais do que buscar contradições lógicas, ou teses que reagem contra outras teses, está o desafio atualíssimo de enriquecer o próprio conceito de razão. Diante de situações concretas, em que se confrontam mundos diferentes, em que horizontes inconciliáveis se enfrentam, cálculo e dedução são insuficientes. Que significa, então, buscar, em meio ao diálogo, coerência e racionalidade? Sem compreender as intenções do outro, sem ouvir o que ele tem a dizer, as questões controversas perderão a chance de se resolver.

Eis que chegamos à tese central de nossa exposição. A abertura à pluralidade de borizontes só é possível quando nos inserirmos no horizonte da reciprocidade sob a forma de efetivação de um espaço transcendental. Para que o diálogo não absorva as subjetividades (e as culturas) num "terreno comum", é preciso resgatar, para além pluralidade das línguas, a língua do universal! Para falar com Levinas, que tanto nos alertou para os perigos $\mathrm{da}$ sabedoria grega, é fundamental guardar os ensinamentos da língua do universal. A língua grega é a da claridade, do método, da progressão do simples ao complexo. E é exatamente por causa disto que ela é também a língua do diálogo, da universidade, da capacidade de valorizar, discutir e ensinar línguas diferentes, de defender a legitimidade de outras culturas, de outros modos de pensar etc. Para Levinas, a Grécia nos transmitiu a linguagem como ato de decifrar, de desmistificar e desmitificar. "É a prosa do comentário, da exegese, da hermenêutica" (LEVINAS, 1988: 65). De nossa parte, perguntamos: não é também a língua do transcendental, tal como Husserl o entende?

\section{A filosofia não é só a língua da Europa, mas pode tornar-se a lingua universal, contanto que a filosofia possa articular-se na sua forma mais autêntica e completa. Se isto tiver êxito, a lingua universal não anulará as linguas particulares, não as reduzirá a instrumentos inferiores, mas assumirá para si a responsabilidade de mediar a peculiaridade dessas linguas, de transmitir os seus impulsos, de salvaguardar os seus valores, de fazer que borizontes diferentes possam se comunicar entre si .(CRISTÍN, 1999: 25)}

Certo, a filosofia do diálogo representa sempre uma crítica contundente à região transcendental de sentido, entendida como suspensão inevitável do movimento real da vida e da linguagem, de tudo o que é "mundano". No entanto, como evitar que os indivíduos e as culturas que se abrem ao

Revista de Filosofia Moderna e Contemporânea

Brasília, vol 3, n 2, 2015. 
Entre fenomenologia e hermenêutica: a condição responsiva da subjetividade

diálogo sejam dissolvidos ou absorvidos por uma cultura em particular, que pretende falar em nome de todas as outras? Só se o espaço transcendental for aquele que, pelo menos em tese, torna possível a interação e o encontro das diferenças ( $c f$. CRISTÍN, 1999: 20). Assim, a língua do universal e a pluralidade das línguas não são termos contraditórios nem implicam filosofias incompatíveis. Sair metodicamente do mundo pré-dado (redução transcendental), bem como abrir-se a outros mundos, dialogicamente, só serão atitudes contrastantes ou excludentes se esquecermos a condição responsiva da subjetividade humana. Descrever a ipseidade ou si-mesmo respondente implica reconhecer dois caminhos que, ao se abrirem, chocam-se e se fecundam mutuamente: o diálogo ultrapassando o âmbito das subjetividades consideradas do ponto de vista do ego, e a redução transcendental (responsiva), sem a qual não se poderia chegar ao "ego absolutamente único" (HUSSERL, 2012: 153). O sujeito transcendental se descobre como sendo único, um eu capaz de responder. Graças a esta unicidade, o diálogo, entendido como busca de uma morada comum, é um belo risco que podemos correr.

\section{Referências bibliográficas:}

CRISTÍN, R.- La filosofia come lingua europea. In: HUSSERL, E.- Crisi e rinascita della cultura europea. Trad. Renato Cristín, Venezia: Marsilio, 1999 (p. 9-26).

GADAMER, H.-G.- El giro hermenêutico. Trad. Arturo Parada, Madrid: Catedra, 1988.

GADAMER, H.-G.- Verità e método (edição bilíngue). Trad. Gianni Vattimo, Milano: Bompiani, 2000.

GADAMER, H.-G.- Linguaggio. Trad. Donatella Di Cesare, Roma-Bari: Laterza, 2005.

GADAMER, H.-G.- Hegel, Husserl, Heidegger. Trad. Marco Antonio Casanova, Petrópolis: Vozes, 2012.

HUSSERL, E.- $A$ crise das ciências européias e a fenomenologia transcendental. Trad. Diogo Falcão Ferrer, Rio de Janeiro: Forense, 2012.

HUSSERL, E.- Meditações cartesianas $e$ Conferências de Paris. Trad. Pedro M.S. Alves, Rio de Janeiro: Forense, 2013.

LEVINAS. E.- A l'heure des nations, Paris : Minuit, 1988.

RICOEUR, P. - Percurso do reconbecimento. Trad. Nicolás Nyimi Campanário, São Paulo: Loyola, 2006.

WALDENFELS, B.- Fenomenologia dell'estraneità. Trad. Gabriella Baptist, Napoli : Vivarium, 2002.

Revista de Filosofia Moderna e Contemporânea

Brasília, vol 3, no 2, 2015. 
WALDENFELS, Fenomenologia dell'estraneo.

Trad. Ferdinando G. Menga, Milano:

Raffaello Cortina Editore, 2008.

Revista de Filosofia Moderna e Contemporânea

Brasília, vol 3, nº 2, 2015. 